\title{
A rare primary epithelial splenic cyst in a 12-year-old boy: A case report and Review of literature
} Asmir Jonuzi $^{1 *}$, Zlatan Zvizdić $^{1}$, Emir Milišić $^{1}$, Irmina Sefić $^{2}$, Melika Bukvić ${ }^{2}$, Amira Mešić ${ }^{3}$, Sanjin Glavaš $^{4}$, Verica Mišanović $^{5}$

${ }^{1}$ Clinic of Pediatric surgery, Clinical Center University in Sarajevo, Patriotske lige 81, 71000 Sarajevo, Bosnia and Herzegovina.

${ }^{2}$ Clinic of Radiology, Clinical Center University in Sarajevo, Bolnička 25, 71000 Sarajevo, Bosnia and Herzegovina.

${ }^{3}$ Clinic for Anaesthesiology and Reanimation, Clinical Center University in Sarajevo, Bolnička 25, 71000 Sarajevo, Bosnia and Herzegovina. ${ }^{4}$ Clinic for Gastroenterology, Clinical Center University in Sarajevo, Bolnička 25, 71000 Sarajevo, Bosnia and Herzegovina.

${ }^{5}$ Pediatric Intensive Care Department, Pediatric Clinic, Clinical Center University in Sarajevo, Patriotske lige 81,71000 Sarajevo, Bosnia and Herzegovina.

*Corresponding Author: Asmir Jonuzi, Ph.D., Clinic of Pediatric surgery; Clinical Center University in Sarajevo; Patriotske lige 81, 71000 Sarajevo; Bosnia and Herzegovina.

Received date: 04 September 2021; Accepted date: 09 October 2021; Published date: 11 October 2021

Citation: Jonuzi A, Zvizdić Z, Milišić E, Sefić I, Bukvić M, et al. (2021) A rare primary epithelial splenic cyst in a 12-year-old boy: A case report and Review of literature. J Med Case Rep Case Series 2(11): https://doi.org/10.38207/JMCRCS/2021/0211166

Copyright: (C) 2021 Asmir Jonuzi. This is an open-access article distributed under the terms of the Creative Commons Attribution License, which permits unrestricted use, distribution, and reproduction in any medium, provided the original author and source are credited.

\begin{abstract}
Splenic cysts are uncommon lesions and are classified as true or pseudocysts based on the presence of an epithelial lining. We report a 12-yearold boy who presented with an abdominal lump associated with pain for 2 months. Ultrasonography of the abdomen showed a huge cystic lesion of obscure origin. MRI abdomen revealed a unilocular cyst of $14 \times 10 \times 12 \mathrm{~cm}$ arising from the spleen. Complete cyst excision with splenic preservation was performed. Histopathological examination revealed it to be a primary epithelial cyst of the spleen. This case report emphasizes the rarity of the case at this age.
\end{abstract}

Keywords: Splenic cyst, Primary epithelial cyst, Spleen.

\section{Introduction}

Splenic cysts (SCs) are extremely rare, with $0.07 \%$ incidence in large series [1]. They are traditionally classified as primary or trueSCs and secondary or falseSCs or pseudo-SCs.The presence of an epithelial lining distinguishes the 2 types. True SCs include parasitic cases, mainly due to Echinococcus granulosus, and nonparasitic cases, which are in turn divided into congenital or epithelial, vascular, and neoplastic (splenic haemangioma, littoral cell angioma, and lymphangioma) [2]. False SCs are secondary to trauma or splenic infarcts [3]. To simplify the classification, some authors consider all non-parasitic SCs as congenital and do not include trauma as a cause

\section{Case Report}

A 12-year-old boy presented to the pediatric surgery department with a dull dragging epigastric and left hypochondriac pain for 2 months. The parents denied any history of abdominal injuries, dyspepsia, and constipation in the past. On physical examination, a firm mass was palpable in the left hypochondrium. Baseline laboratory investigations including hemoglobin, complete blood count were normal. Serological tests for HBsAg and HIV were nonreactive. Indirect haemagglutination test and enzyme-linked immunosorbent assay for detection of anti-Echinococcus antibodies were negative. While AFP, bHCG, and alpha-fetoprotein were negative. The physical of SCs because post-traumatic lesions are simple intrasplenic hematomas that have failed to organize in the usual manner [4]. The increased risk of overwhelming post-splenectomy infection in children has prompted organ-saving procedures: partial splenectomy [5]; simple percutaneous aspiration or sclerosis of the cyst [6]; and partial cyst amputation [7]. A significant risk of recurrence is commonly reported for all of them. Most recently, Touloukian et al. [8]. proposed partial decapsulation of splenic epithelial cysts (SEC) to preserve splenic function.

examination revealed a large spleen and US demonstrated a huge cystic lesion of obscure origin. On MRI of the whole abdomen, a large exophytically bulging well defined cystic lesion is seen measuring 14x10x12cm and replacing upper and mid part of spleen, extending superiorly up to the left dome of the diaphragm, medially indenting posterior and lateral wall of the stomach and indenting the tail of the pancreas (Figure 1). A clinical and radiological impression of pseudocyst was made. At laparotomy, a huge unilocular cyst involving the upper part of the spleen containing serous fluid was found (Figure 2). Intraoperative aspiration of the cystic area resulted 
in $1000 \mathrm{ml}$ of serous fluid. Complete cyst excision with splenic preservation was performed Final histopathological diagnosis of an epidermoid cyst spleen was made. The postoperative course was uneventful and the child was discharged after 7 days of operation. Pathological examination showed an epidermoid congenital cyst.

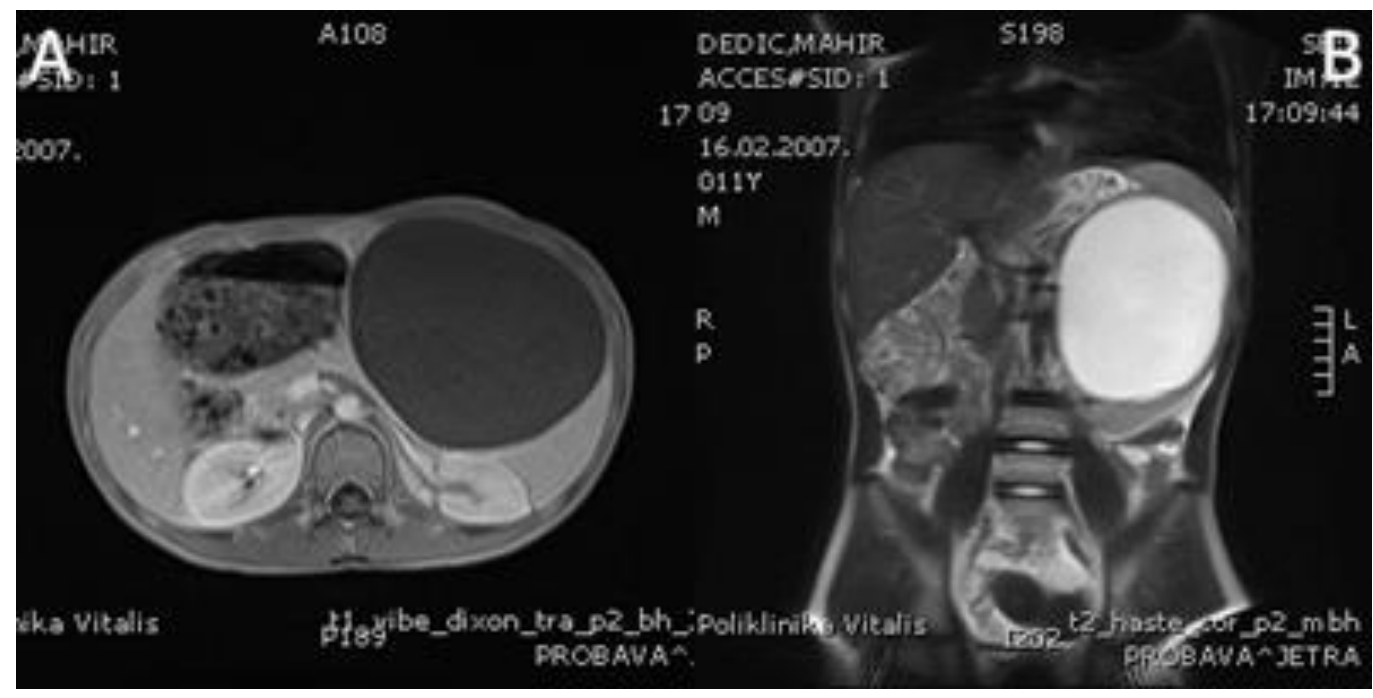

Figure 1: Axial (A) and coronal (B) magnetic resonance imaging revealing a well defined clear cystic lesion from spleen

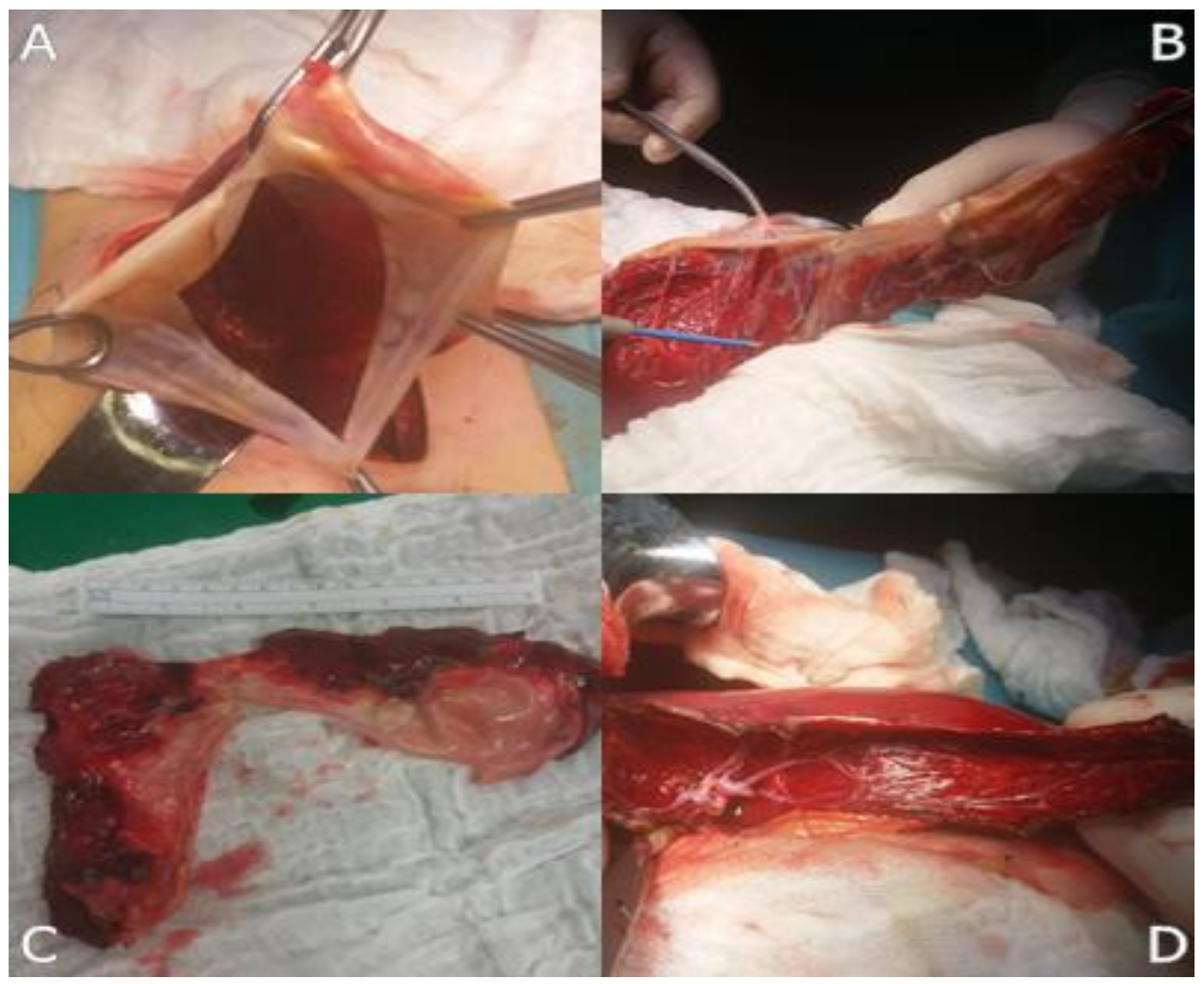

Figure 2: Intraoperative pictures: (A) Spleen with epidermoid cyst; (B) Greyish white glistening cyst wall with marked trabeculations; (C) Removed splenic cyst; (D) Final appearance of splenic parenchyma

\section{Discussion}

Cystic lesions are among the unusual lesions of the spleen which include parasitic and non-parasitic cysts. The non-parasitic cysts are still rarer and divided into true cysts having an epithelial lining (epidermoid, dermoid, and mesothelial) or endothelial lining (haemangioma, lymphangioma) and secondary (pseudocysts/nonepithelial), which are generally of post-traumatic origin [9]. The epithelial cysts are the most common type of nonparasitic splenic cyst. Their global incidence is 0.007 with a female predominance. The pathogenesis of primary splenic cysts is not clear [10]. Primary cysts are also called true, congenital, epidermoid, or epithelial cysts. As per the existing literature, since the first case was reported in 1929 by Andral, the classification of these lesions has evolved into the present system [11]. Epidermoid cysts are thought to arise from the inclusion of splenic surface mesothelium into the splenic parenchyma during development. Mostly asymptomatic these cysts cause symptoms only if they acquire a size of $5 \mathrm{~cm}$ or more by the second or third decade of life; though our patient became symptomatic in the second decade. Common symptoms are dull aching pain with left upper quadrant fullness. Complications include rupture with abdominal trauma, hypertension due to renal compression, infection, hypersplenism, hemorrhage within the cyst, and even malignant degeneration [4]. In our patient abdominal tenderness was present along with pain. The differential diagnosis could be splenic lesions like lymphangioma, haemangioma, hydatid cyst, bacterial abscess, cystic metastasis, and intrasplenic pancreatic pseudocyst. Radiological investigations like ultra-sonogram, CT 
scanning or MRI may help in identifying the morphology, composition of cystic fluid, and their location in the spleen but the final diagnosis depends on the histopathological examination of the cyst $[\mathbf{1 2 , 1 3}]$. The epidermoid cyst exhibits unique gross features with a grey-white, smooth and glistening wall having prominent trabeculations [4]. The cyst contains thin to viscid, colorless to brownish fluid. Histologically it is characterized by squamous epithelial lining or a single layer of flattened epithelium without skin appendages. Desquamation of epithelium may lead to loss of lining in some portions of the wall. Splenic cysts have historically been treated by splenectomy. The fragile spleen, hidden in its left upper quadrant recess, always presents an interesting and difficult challenge to the surgeon, while the presence of an epidermoid cyst makes it an even harder challenge. Currently, the trend has shifted to more conservative surgery with the demonstration of increased mortality of

\section{Conclusion}

Once diagnosed, elective surgical management is advised for larger symptomatic splenic cysts to prevent complications. This case is reported because of the relative rarity of this type of cyst and because it presents such characteristic findings as young age group, the absence of acute symptoms except for the space-occupying lesion in the upper abdomen, its recent rapid growth, and vague abdominal pain. Complete cystectomy using an open surgery approach was successfully performed for this case with a massive splenic cyst encroaching the hilum. Because of the rarity of splenic cysts in the

\section{References}

1. Macheras A, Misiakos EP, Liakakos T, Mpistarakis D, Fotiadis C, et al. (2005) Non-parasitic splenic cysts: A report of three cases. World J Gastroenterol. 11(43): 6884-6887.

2. Shabtaie SA, Hogan AR, Slidell MB (2016) Splenic cysts. Pediatr Ann. 45(7): e251-6.

3. Martin JW (1958) Congenital splenic cysts. Am J Surg. 96(2): 302-8.

4. Morgenstern L (2002) Nonparasitic splenic cysts: pathogenesis, classification, and treatment. J Am Coll Surg. 194: 306-14.

5. Brown MF, Ross AJ, Bishop HC, Schnaufer L, Ziegler MM, et al. (1989) Partial splenectomy: the preferred alternative for the treatment of splenic cysts. J Pediatr Surg. 24(7): 694-696.

6. Moir C, Guttman F, Jequier S, Sonnino R, Youssef S (1989) Splenic cysts: aspiration, sclerosis, or resection. J Pediatr Surg. 24(7): 646-648.

7. Domini M, Aquino A, Rossi C, Pappalepore N, Valentini M, Lelli Chiesa P. Cisti splenica gigante: trattamento chirurgico mediante decapsulazione parziale. RICP 1996;38: 68-71.

8. Touloukian RJ, Maharaj A, Ghoussoub R, Reyes M (1997) Partial decapsulation of splenic epithelial cysts: studies on etiology and outcome. J Pediatr Surg. 32(2): 272-274. splenectomized patients due to overwhelming post-splenectomy sepsis. Because of the increased risk of complications, splenic cysts with a diameter larger than 4-5 cm should be managed surgically [14] because conservative options, such as percutaneous aspiration or sclerosis, do not result in long-term control. The classical approach to splenic cysts has been open complete splenectomy. Today, the options are percutaneous aspiration or percutaneous drainage, partial splenectomy with a stapler or harmonic scalpel, total cystectomy, marsupialization, or cyst decapsulation (unroofing), laparoscopic puncture, and creation of a cyst peritoneal window. Access can be either by open laparotomy or laparoscopy. Partial splenectomy preserves more than $25 \%$ of the splenic parenchyma, which is the minimal splenic tissue to preserve immunologic protection without increasing the risk of recurrence $[\mathbf{1 1 , 1 5}]$.

pediatric population, there is a paucity of definitive guidelines for the management of splenic cysts, but the importance of a spleenpreserving approach is well received as the immunological function of the spleen can be preserved. Splenectomy should only be reserved as a last resort.

Declaration of patient consent: The authors certify that they have obtained all appropriate patient consent forms

9. Dalal S, Verma M, Vashist MG (2013) Epidermoid cyst of the spleen. IJRRMS. 3: 47-48.

10. Mahore K, Hoogar MB, Dhar R, Jain A, Pereira E (2017) Primary Epithelial Cyst of Spleen - A Case Report. Int J Res Rev. 4(1): 525.

11. Kala PS, Azad S, Sharma T, Acharya S (2019) Primary epithelial splenic cyst: A rare encounter. Indian J PatholMicrobiol. 62(4): 605-7.

12. Hansen MB, Moller AC (2004) Splenic cysts. Surg Laparosc Endosc percutan Tech. 14(6): 316-22.

13. Robertson F, Leander P, Ekberg O (2001) Radiology of the spleen. Eur Radiol. 11(1): 80-95.

14. Till H, Schaarschmidt K (2004) Partial laparoscopic decapsulation of congenital splenic cysts. Surg Endosc. 18(4): 626-8.

15. Zvizdić Z, Karavdić K (2013) Spleen-preserving surgery in treatment of large mesothelial splenic cyst in children--a case report and review of the literature. Bosn J Basic Med Sci. 13(2): 126-8. 